
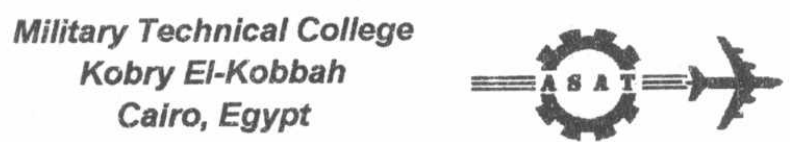

$10^{\text {th }}$ International Conference

On Aerospace Sciences\&

Aviation Technology

\title{
EFFECT OF GAMMA RADIATION ON SOME SYNTHETIC INORGANIC ION EXCHANGERS
}

\author{
Tadrous, N.A. and Morcos, T.N. \\ Nuclear Chemistry Department, Hot Laboratories Center Atomic Energy \\ Authority, \\ P. Code, 13759, Egypt
}

\begin{abstract}
Ion exchange properties and radiation stability for synthesized hydrous tin, ferric and mixed $\mathrm{Fe}(\mathrm{III}) \mathrm{Sn}(\mathrm{IV})$ oxides have been investigated. These hydrous oxides were obtained by precipitation with ammonia from metal chloride solutions. The prepared samples were exposed to different doses of gamma radiation ranging from 1 MGy up to 5 MGy. The effect of various doses of gamma radiation on both the structure and ion exchange sorption has been studied.

The structural features of non-irradiated and irradiated samples were investigated through I.R ، X-ray and surface area. No change has been observed in the structure of microcrystalline hydrous tin oxide as the gamma dose increases while hydrous ferric and mixed oxides showed slight changes .

Sorption behavior for all samples was examined using mono, di, and trivalent cations. The capacity and $k_{d}$ values did not markedly altered with increasing gamma radiation dose for all the aforementioned oxides. It can be generally concluded that these oxides exhibit high radiation stability towards $\gamma$-radiation doses.
\end{abstract}

\section{KEY WORDS}

Hydrous oxides, sorption, inorganic ion exchangers, effect of $\gamma$-radiation dose, and radiation stability. 


\section{INTRODUCTION}

Much attention has been paid during the last decades to the development of synthetic inorganic ion exchangers, in the field of nuclear chemical engineering and radiochemical separation processes [1 - 4]. Synthetic inorganic ion exchangers are composed mainly of hydrous oxides, acidic salts of multivalent metals, salts of heteropolyacids, insoluble ferrocyanides and synthetic clays and zeolites. They are expected to have higher radiation and thermal stability.

As a fact, the ion exchange materials are exposed to radiation, from radioactive nuclides, during sorption of radioactive nuclides in the treatment of radioactive waste solutions and hence must posses high radiation and thermal stability. The data on radiation stability of different ion exchangers, especially those of inorganic ones, are limited where few reports are available in the literature [1, $4-12]$. However, there are a great stability for inorganic ion exchangers than organic resins but this rule can't be generalized $[8,13]$.

Few studies have been previously published on thermal stability of hydrous tin, ferric and mixed Fe-Sn oxides [14], but the effect of $\gamma$-irradiation doses has not been investigated. The present work is oriented to investigate the radiation stability of this group of inorganic ion exchangers (hydrous oxides) and emphasizing their applicability to the removal of radioactive nuclides from the liquid waste streams.

\section{EXPERIMENTAL}

The chemicals used through this study were of analytical grade reagents. The inorganic ion exchangers, hydrous tin, ferric and mixed tin-ferric oxides (hereafter designated HTO, HFO and HMO respectively) were prepared following the same previously published procedure [14].

Samples of the prepared hydrous oxides were placed in a special vial in $\gamma$-irradiation cell and exposed to different $\gamma$-radiation doses ranging from 1 MGy up to 5 MGy for various times to obtain the desired doses. The working dose rate during the period of irradiation was $2.083 \mathrm{~Gy} / \mathrm{s}$. The Russian gamma ${ }^{60} \mathrm{Co}$ irradiation facility "Issledovate" at the National Center for Radiation Research and Technology, Atomic Energy Authority in Egypt was used.

The structural features were examined using $x$-ray, infrared and specific surface area techniques that carried out for all samples, before and after being irradiated to different $\gamma$-doses. X-ray patterns were obtained using SHIMADZO $x$-ray diffractometer, model XD-D1, with $\mathrm{Ni}$ filtered and $\mathrm{Cu}-\mathrm{K}_{\alpha}$ radiation. The system was operated at $30 \mathrm{kV}$ and $30 \mathrm{~mA}$ and the scanning speed was $8 \% \mathrm{~min}$. Infrared analysis was performed using a fully automatic infrared POMEN, Hartman spectrometer, model MB157, Canada. The spectra were scanned over the frequency range 400$4000 \mathrm{~cm}^{-1}$. The specific surface areas for all samples were determined using NOVA 3200, Version 6.08 High Speed Gas Sorption Analyzer. The $\mathrm{N}_{2}$ adsorption was achieved at liquid nitrogen temperature of $77 \mathrm{~K}$. 
Sorption behavior was evaluated in terms of capacity and distribution ratio, $k_{d}$ for all samples before and after irradiation. The capacity was measured by repeated equilibration with chloride solutions of $\mathrm{Cs}^{+}, \mathrm{Co}^{2+}$ and $\mathrm{In}^{3+}$ ions, labeled with radioactive ${ }^{134} \mathrm{Cs},{ }^{60} \mathrm{Co}$ and ${ }^{114} \mathrm{In}$ respectively. $0.05 \mathrm{~g}$ of the dry exchangers were equilibrated with $2.5 \mathrm{~mL}\left(\mathrm{v} / \mathrm{m}=50 \mathrm{~cm}^{3} / \mathrm{g}\right)$ of $0.01 \mathrm{~mol} / \mathrm{L} \mathrm{CsCl}$ solution at a pH $=9.5$ in a shaker thermostated at $29^{\circ} \mathrm{C}$ for 24 hours. Repeated equilibration for three times were carried out until no further uptake of cesium occurred. The same procedure was followed in cases of $\mathrm{CoCl}_{2}$ and $\mathrm{InCl}_{3}$, except with a concentration of $0.1 \mathrm{~mol} / \mathrm{L}$, $\mathrm{v} / \mathrm{m}=10 \mathrm{~cm}^{3} / \mathrm{g}$ and $\mathrm{pH}=5.5$ for $\mathrm{CoCl}_{2}$, and $5 \times 10^{-3} \mathrm{~mol} / \mathrm{L}, \mathrm{v} / \mathrm{m}=100 \mathrm{~cm}^{3} / \mathrm{g}$ and $\mathrm{pH}=3.7$ for $\mathrm{InCl}_{3}$. The amount of metal adsorbed was calculated from the difference between the initial and final activity of the aqueous phase with an ORTEC EG\&G Scalar connected to a well type $\mathrm{Nal}$ scintillation detector. The capacity in $\mathrm{mmol} / \mathrm{g}$ was calculated applying the following equation:

$$
\text { Capacity }=\frac{\% \text { uptake }}{100} \times \mathrm{C}_{0} \times \mathrm{v} / \mathrm{m}
$$

where, $\mathrm{C}_{0}$, is the initial concentration of solution in $\mathrm{mol} / \mathrm{L}$

$\mathrm{v}$, is the volume of solution in $\mathrm{ml}$

$\mathrm{m}$, is the weight of the exchanger in $\mathrm{g}$

Obviously, the value of the capacity is multiplied by the unite charge (valency) of the adsorbed cation to have the capacity in $\mathrm{meq} / \mathrm{g}$.

The distribution ratios, $k_{d}$, for the mono-, di- and trivalent cations were measured for non-irradiated and irradiated samples. A chloride solutions of $1 \times 10^{-4} \mathrm{~mol} / \mathrm{L}$ of $\mathrm{Cs}^{+}$, $\mathrm{Co}^{2+}$ and $\mathrm{In}^{3+}$ ions were mixed with the exchangers, at a v/m $=100 \mathrm{~cm}^{3} / \mathrm{g}$ and $\mathrm{pH}=7$ in case of $\mathrm{Cs}^{+}$ion, while for both $\mathrm{Co}^{2+}$ and $\mathrm{In}^{3+}$ the $\mathrm{v} / \mathrm{m}=200 \mathrm{~cm}^{3} / \mathrm{g}$ and the $\mathrm{pH}=6.2$ and 5.5 respectively. The amount of metal ion sorbed was determined as mentioned above from the difference between the initial and final activity. The distribution ratio values were calculated as follow:

$$
k_{d}=\frac{\% \text { uptake }}{100-\% \text { uptake }} \times \mathrm{v} / \mathrm{m}
$$

\section{RESULTS AND DISCUSSION}

\section{Structural Features}

\section{1.a X-RAY}

X-ray diffraction patterns for samples before irradiation to $\gamma$-dose [Figs. 1-a, 2-a and (3)-a] indicate that all samples are amorphous. In a previous study, hydrous tin oxide was found to be microcrystallin [14] as it gave diffuse peaks corresponding to the mineral cassiterite (anhydrous stannic oxide) [15]. Figures 1-3 (b and c) represent $\mathrm{X}$-ray patterns for the investigated samples after being irradiated to 2 and $5 \mathrm{MGy}$ respectively. They all posses the same diffraction patterns as the original samples (before irradiation). As the $\gamma$-dose increases, very small shifts are observed in the values of $2 \theta$ or relative intensities as observed in tables accompanied by patterns 


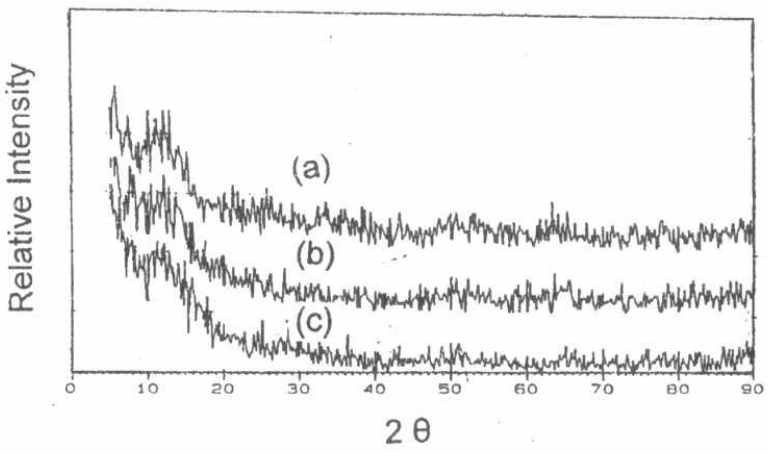

Fig. (1): X-ray diffraction of hydrous tin oxide before irradiation (a), and after being irradiated with 2 MGy (b), 5 MGy (c).

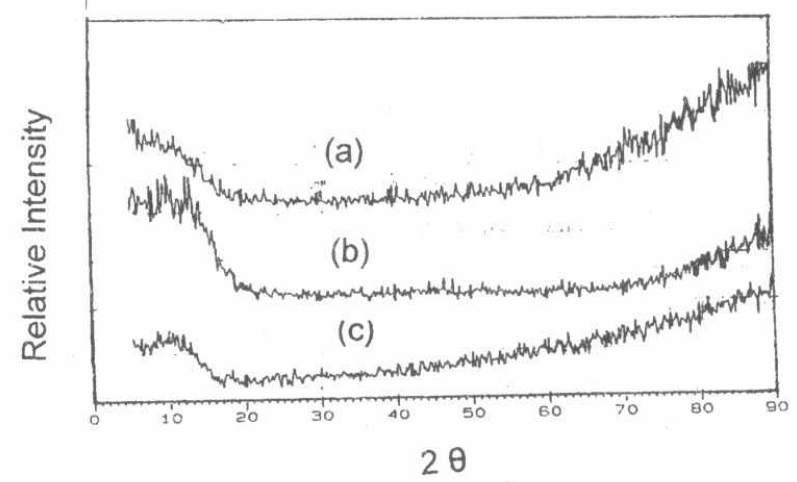

Fig. (2): X-ray diffraction of hydrous ferric oxide before irradiation (a), and after being irradiated with 2 MGy (b), 5 MGy (c).

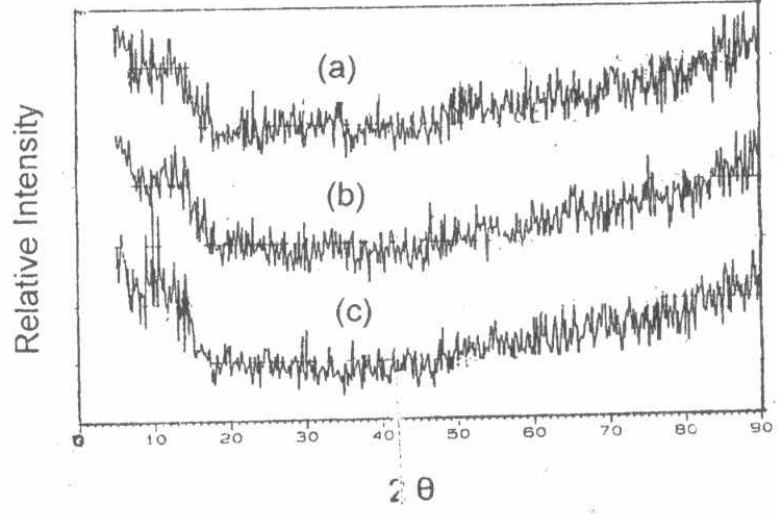

Fig. (3): X-ray diffraction of hydrous mixed oxide before irradiation (a), and after being irradiated with 2 MGy (b), 5 MGy (c). 
(not given here for the brevity). However, these small shifts do not alter the structure of the samples. Also, Lehto and szirtes [16], observed a slight increase in lattice parameter and a slight decrease in broadness of the reflections in the X-ray diffraction patterns of the irradiated cobalt hexacyanoferrate (II).

\section{1.b Infrared, I.R}

Infrared spectra of the samples before and after exposed to different $\gamma$-doses are shown in Figs 4 - 6. Figure 4 - a displayed the I.R pattern of HTO that has a broad band at about $3700-2500 \mathrm{~cm}^{-1}$ attributed to $\mathrm{OH}$ groups and water molecules. A band at about $1625 \mathrm{~cm}^{-1}$, very small peak at $1420 \mathrm{~cm}^{-1}$ and a small broad band at about $1350-1250 \mathrm{~cm}^{-1}$, are due to water molecules. A broad band at about $800-350$ $\mathrm{cm}^{-1}$ with a shoulder at about $660 \mathrm{~cm}^{-1}$ and a very small band at $564 \mathrm{~cm}^{-1}$ may be attributed to $\mathrm{Sn}-\mathrm{O}$ vibrations $[17,18]$. The spectra of HTO irradiated to different $\gamma$-doses 1, 3, and 5 MGy, Fig. 4 b-d respectively show no significant structure changes.

Figure 5-a has shown the I.R pattern of HFO before being irradiated, it comprise a broad band containing a peak at about $3370 \mathrm{~cm}^{-1}$ which is due to the stretching vibrations of water molecules and $\mathrm{OH}$ groups $[19,20]$. The Figure has shown also, a band at about $1600 \mathrm{~cm}^{-1}$ attributed to the bending vibrations of water molecules [20], and two small bands at about 1520 and $1340 \mathrm{~cm}^{-1}$ probably due to water molecules [21]. In addition a medium band at about $1060 \mathrm{~cm}^{-1}$ is probably due to $\mathrm{Fe}-\mathrm{OH}$ vibrations [17, 22], and a small broad band at about $550-350 \mathrm{~cm}^{-1}$ with a peak at about $450 \mathrm{~cm}^{-1}$ which can be attributed to $\mathrm{Fe}-\mathrm{O}$ vibrations $[17,18]$. No specific changes have been observed in the I.R spectra of HFO after being irradiated to 1,3 or 5 MGy (Fig 5 b-d).

The I.R spectra of HMO Fig. 6 are similar to those of HTO specially the band due to $\mathrm{OH}$ groups and water molecules. However, in previous study [14], It had been proved that HMO do not behave as a simple mixture of HFO and HTO. A very large band at about $800-400 \mathrm{~cm}^{-1}$ incorporating two small peaks at 650 and $540 \mathrm{~cm}^{-1}$ incorporating two small peaks at 650 and $540 \mathrm{~cm}^{-1}$ may be attributed to $\mathrm{M}-\mathrm{O}$ vibrations.

It can be concluded from $X$-ray and I.R analyses that the structure of the investigated samples, HTO, HFO and HMO, remained practically unaltered when irradiated up to $5 \mathrm{MGy}$. That is to say, as these samples can stand for such high radiation doses they can be applied as potential adsorbents in the treatment of radioactive waste.

\section{1. c Surface Area}

The specific surface area data obtained by nitrogen adsorption is given in Table 1 and it gives the area of all exposed surfaces to which the $\mathrm{N}_{2}$ molecules can reach (micropores, mesopores, macropores). The slight increase of specific surface area in HTO as the $\gamma$-dose increase up to 5 MGy can be attributed to a formation of new pores as the $\gamma$-radiation can affect the texture of some inorganic ion exchangers [23]. 


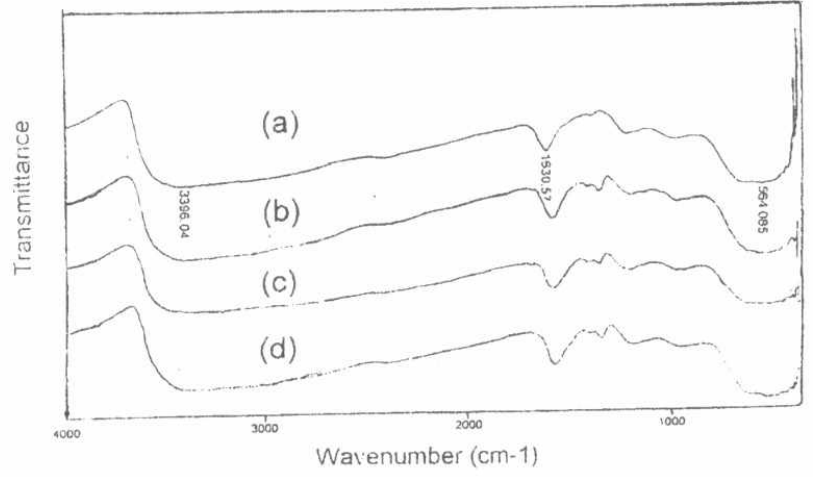

Fig. (4): Infrared spectra of hydrous tin oxide before irradiation; (a), and after being irradiated with $1 \mathrm{MGy}$; (b), 3 MGy; (c), and 5 MGy; (d).

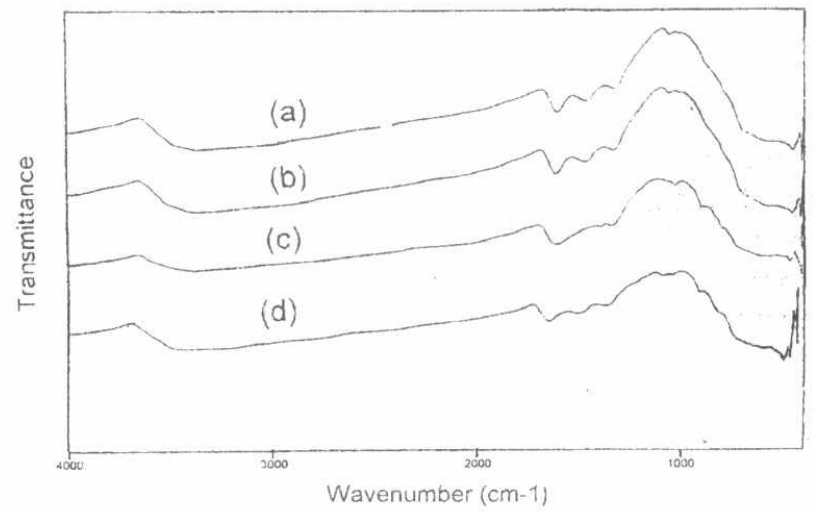

Fig. (5): Infrared spectra of hydrous ferric oxide before irradiation; (a), and after being irradiated with 1 MGy; (b), 3 MGy; (c), and 5 MGy; (d).

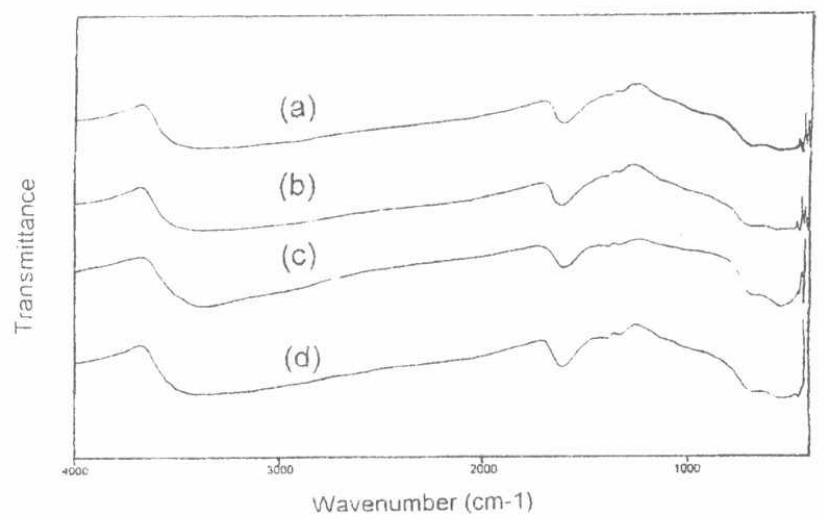

Fig. (6): Infrared spectra of hydrous mixed oxide before irradiation; (a), and after being irradiated with $1 \mathrm{MGy}$; (b), $3 \mathrm{MGy}$; (c), and 5 MGy; (d) 
However, the specific surface area of both HFO and HMO decreases with the increase of $\gamma$ - dose. Lehto and Szirtes [16] have found that the crystal size of hexacyanoferrate increases as a result of increasing irradiation dose and the specific surface area decreases. That is to say, certain changes may be accompanied by irradiating inorganic ion exchangers but without any structural changes.

Table 1: Variation of specific surface area with $\gamma$ - dose for different hydrous oxides.

\begin{tabular}{|c|c|c|}
\hline Hydrous Oxide & Dose, MGy & $\begin{array}{c}\text { Specific Surface Area, } \\
\mathbf{~}^{\mathbf{2}} / \mathbf{g}\end{array}$ \\
\hline \multirow{3}{*}{ HTO } & 0 & 149.6 \\
& 2 & 156.1 \\
5 & 163.2 \\
\hline HFO & 0 & 233.5 \\
& 2 & 205.1 \\
& 5 & 193.5 \\
\hline HMO & 0 & 257.0 \\
& 2 & 230.3 \\
& 5 & 213.0 \\
\hline
\end{tabular}

\section{Sorption Behavior}

\section{2.a- Apparent Capacity for mono-, di- and trivalent cations}

The effect of different $\gamma$-radiation doses on sorption capacity, for $\mathrm{Cs}^{+}, \mathrm{Co}^{2+}$ and $\mathrm{In}^{3+}$ ions on different examined hydrous oxides, are represented in Fig 7. There is only small increase in capacity at high doses for $\mathrm{HTO}$, and slight decrease in capacity for both HFO and HMO. The crystal structure may have been slightly affected but without any chemical changes. The trend of adsorption is nearly the same for the three tested ions, $\mathrm{Cs}^{+}, \mathrm{Co}^{2+}$ or $\mathrm{In}^{3+}$, with a very little increase or decrease in the values of capacity. This can be directly related to the variation in the surface area of different oxides upon irradiation. Table 1 illustrates the change of the specific surface area after irradiation with different doses. The increases in surface area show that some of the pore surfaces may contribute to the exchange.

Many authors [16, 24-25] discussed the variation of capacity or distribution ratio with $\gamma$-radiation doses. It has been proved $[16,26]$ that there is a change of crystal size and specific surface area as a result of increasing $\gamma$-radiation doses and consequently sorption properties may be affected (such as capacity and distribution ratio). Similarly, Venkataramani et al. [25] have observed certain physical changes on irradiating hydrous titanium oxide samples. 

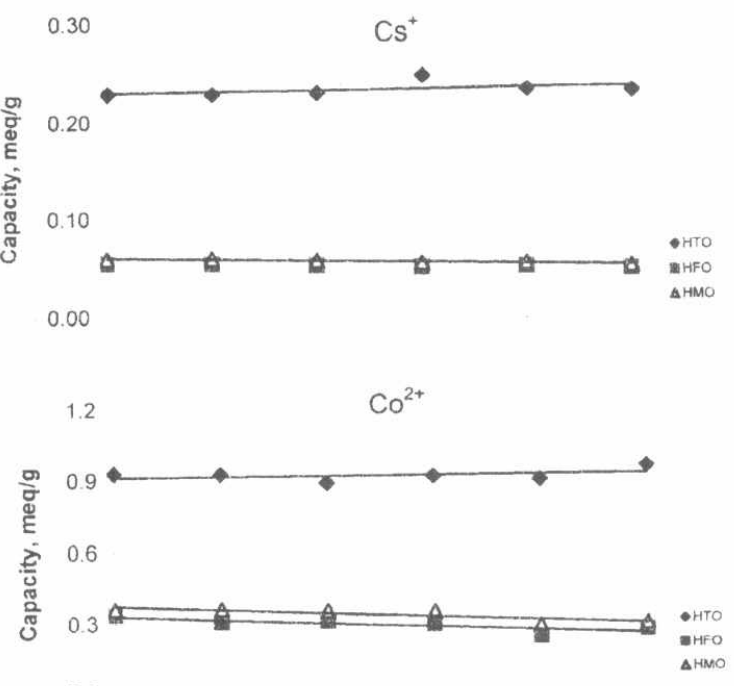

0.0

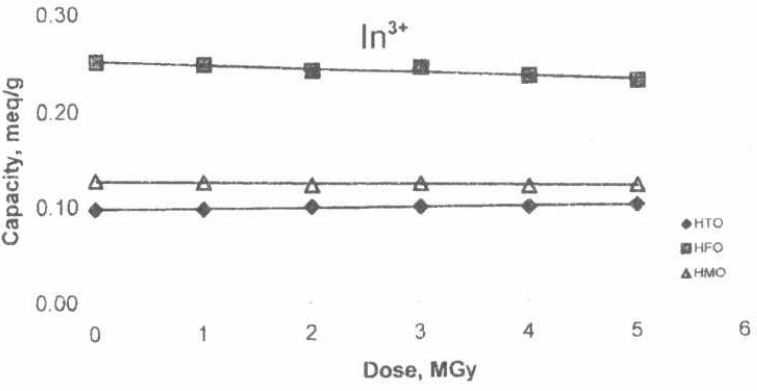

Fig. (7): Effect of gamma irradiation dose on the capacity of different hydrous oxides for $\mathrm{Cs}^{+} \mathrm{Co}^{2+}$ and $\mathrm{In}^{3+}$ ions 


\section{2.b- Distribution Ratio, $\mathbf{k}_{\mathbf{d}}$}

The plots of $\log k_{d}$ versus $\gamma$-irradiation dose are shown in Fig 8 for the investigated samples. The examined hydrous oxides follow nearly the same trends mentioned earlier on the capacity which confirm that the $\gamma$-radiation dose does not affect significantly the sorption properties of these hydrous oxides. Varshney, et al., [24] studied the distribution ratio for alkaline earth's, $\mathrm{Mg}$ (II), $\mathrm{Ca}$ (II), $\mathrm{Sr}$ (II) and $\mathrm{Ba}$ (II) at different media on some inorganic ion exchangers and they found that the $k_{d}$ values obtained, generally, increase with the total dose absorbed. They observed that zirconium (IV) arsenosilicate, before irradiation, gave almost similar $k_{d}$ values for the four alkaline earth's studied while an irradiated to $2 \times 10^{8}$ rads (2MGy) gave a high selectivity for $\mathrm{Ba}$ (II). At the same work, it has been found that antimony (IV) silicate showed a peculiar distribution behavior in the same media where irradiation was found to lower the $\mathrm{k}_{d}$ value of $\mathrm{Ca}$ (II) but not that of $\mathrm{Mg}$ (II). On the other hand, thorium phospho silicate or stannic arsenosilicate did not show any change in their $k_{d}$. Other authors [16] found that the higher the dose, the lower was the uptake of $\mathrm{Cs}^{+}$ions on potassium cobalt hexacyanoferrate (II) and the distribution coefficient values.

The results obtained in this work confirm the stability of hydrous tin, ferric and mixed $\mathrm{Sn}-\mathrm{Fe}$ oxides toward high doses of $\gamma$-rays. The structural features and sorption behavior of these inorganic ion exchangers reflect their importance in application in different fields. These groups of inorganic ion exchangers are considered as potential adsorbents for the treatment of radioactive wastes. Besides, they can be applied for the removal of many pollutants arising from different origins. 

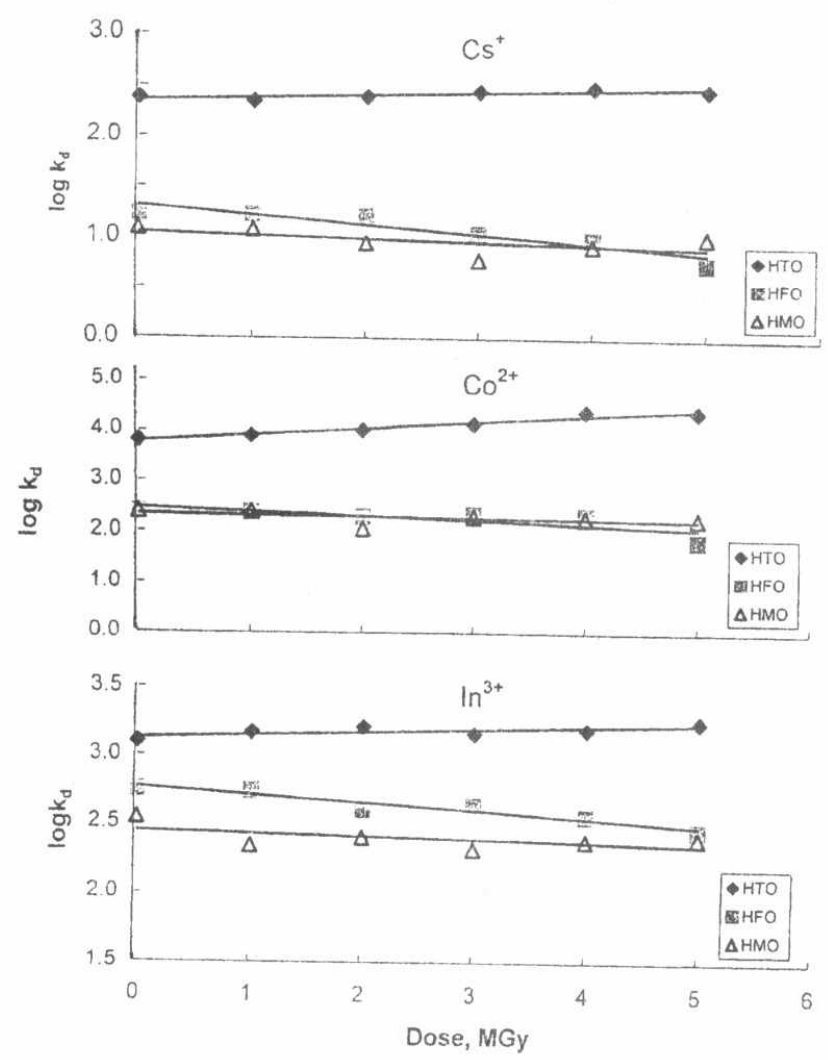

Fig.(8): Effect of different gamma radiation doses on the distribution ratio, $\mathrm{kd}$, of hydrous tin, ferric and mixed $\mathrm{Sn}$-Fe oxides. 


\section{REFERENCES}

[1] Amphlett, C.B., Inorganic Ion Exchangers, Elsevier, Amsterdam, (1964).

[2] Vesely, V. and Pekarek, V., Talanta, 19, pp 1245, (1972).

[3]Clearfield, A., Nancollas, G.H. and Blessing, R.H., in Ion Exchange and Solvent Extraction, Vol. 5, Marinsky, J.A. and Marcus, Y. (Eds), Marcel Dekker, New York, (1973).

[4]Singh, N.J. and Tandon, S.N., J. of Radioanal. Chem. 49, 195 (1979).

[5] Zsinka, L., Szirtes, L. and Stenger, V., Radio Chem. Radioanal. Lett., vol. 4, 257, (1970).

[6] Qureshi, M., Varshney, K.G. (eds.), Inorganic Ion Exchangers In Chemical Analysis, CRC Press, Boca Raton, Ann Arbor, Boston, (1991).

[7]Botros, N., Arab J. of Nuclear Sciences and Applications, vol. 29(4), pp 251-266. (1996).

[8]Zsinka, L., Szirtes, L., Mink, J. and Kalman, A., J. Inorg. Nucl. Chem., vol. 36, 1147, (1974).

[9]Szirtes, L. and Zsinka, L., J. of Radioanal. Chem., vol. 21, 367, (1974).

[10]Zsinka, L., Szirtes, L. and Mink, J., J. of Radioanal. Chem., vol. 30, 139, (1976).

[11]Varshney, K.G., Varshney, K. and Agrawal, S., Separation Science and Technology, vol. 18, 905, (1983).

[12]Varshney, K.G., Agrawal, S., Varshney, K., Sharma, V. and Rani, S., J. Radioanal. Nucl. Chem. Art., vol. 82(2), 299 (1984).

[13]Mathew, J., Tandon, J.S. and Gill, J.S., Radiochem. Radioanal. Lett., 30, pp 381, (1977).

[14] Morcos, T.N., M.Sc. Thesis, Cairo University, Cairo, Egypt, (1996).

[15] ASTM Cards of X-ray Patterns, American Society for Testing Materials .

[16] Lehto, J.S., and Szirtes, L., Radiat. Phys. Chem., 43(3), pp. 261, (1994).

[17] Gladsden, J.A., Infrared Spectra of Minerals and Related Inorganic Compounds, Butter Worths, London, (1975). 
[18] Abe, M., in A. Clearfield (Ed.), Inorganic Ion Exchange Materials, CRC Press, Boca Raton, FL, chapter 6, (1982).

[19] Lawson, R.E., Infrared Absorption of Inorganic Substances, Reinhold, New York, (1961).

[20] Nakamoto, K., Infra red Spectra of Inorganic and Coordination Compound, Wiely, New York, (1963).

[21] Shafik, S.S., Ph.D Thesis, Ain Shams University, Cairo, (1989).

[22] Mahal, H.S., Venkataramani, B., and Venkateswarlu, K.S., J. of Inorg. Nucl. Chem., 43, pp 3335, (1981).

[23] Morcos, T.N., Ph.D Thesis, Ain Shams University, Faculty of Science, Cairo, Egypt, (2001).

[24] Varshney, K.G., Agrawal, S., Varshney, K., Sharma, U., and Rani, S., J. of Radioanal. Nucl. Chem., 82(2), 299 (1984).

[25] Venkataramani, B., Gupta, A.R. and lyer, R.M., J. Radioanal. Nucl Chem., Lett. 96(2), pp 129-136, (1985).

[26] Lehto, J.S., Haukka, S., Harjula, R., and Blomberg, M., J. of Chem. Soc . Dalton Trans., 3, pp. 1007, (1990). 